\title{
Bioflocculant BF-R1 production by Bacillus sp. R1 using wheat bran hydrolysate and its application in wastewater treatment
}

\author{
Rexiding Abuduaini ${ }^{1,{ }^{\dagger}}$, Na-Ling Bai ${ }^{2{ }^{\dagger}}$, Cai Hui ${ }^{1}$, Sheng Wang ${ }^{1}$, Hui Jiang ${ }^{1}$, Yu-Hua Zhao ${ }^{1,{ }^{*}}$ \\ ${ }^{1}$ Institute of Biochemistry, College of Life Sciences, Zhejiang University, Hangzhou 310058, P.R. China \\ ${ }^{2}$ Eco-environmental Protection Research Institute, Shanghai Academy of Agricultural Sciences, Shanghai 201403, China \\ ${ }^{\dagger}$ Contributed equally to this work
}

\begin{abstract}
Bioflocculants are commonly used in wastewater treatment. In this study, an efficient bioflocculant-producing strain, Bacillus sp. $\mathrm{R} 1$, was isolated and identified; strain R1 could efficiently produce bioflocculant BF-R1 with wheat bran hydrolysate. The characteristics and flocculation mechanisms of BF-R1 were determined and it was then applied for the granular carbon particles treatment in wastewater. Notably, $3.71 \mathrm{~g}$ of BF-R1 were produced when $200 \mathrm{~mL} / \mathrm{L}$ wheat bran hydrolysate was used as the sole carbon and nitrogen source. BF-R1 contained polysaccharides, proteins, and glycoproteins and showed a good flocculating efficiency of $91.00 \%$ for granular carbon particles in contaminated wastewater when $3.50 \mathrm{~g} / \mathrm{L}$ BF-R1 was added, thus achieving successful recycling of fine particle-contaminated wastewater. Taken together, our findings for the first time demonstrate that BF-R1 fermented using WBH can probably be a promising candidate agent for wastewater management processes.
\end{abstract}

Keywords: Bioflocculant, Bacillus sp. R1, wheat bran hydrolysate, granular carbon particles, flocculation efficiency

${ }^{*}$ Correspondence to: Yu-Hua Zhao, Institute of Biochemistry, College of Life Sciences, Zhejiang University, Hangzhou 310058, P.R. China;

E-mail: yhzhao225@zju.edu.cn

Received: March 25, 2019; Accepted: November 5, 2019; Published Online: December 24, 2019

Citation: Yu-Hua Zhao et al., 2019. Bioflocculant BF-R1 production by Bacillus sp. R1 using wheat bran hydrolysate and its application in wastewater treatment. Applied Environmental Biotechnology, vol.5(1): 25-33. http://doi.org/10.26789/AEB.2019.02.005

Copyright: Bioflocculant BF-R1 production by Bacillus sp. R1 using wheat bran hydrolysate and its application in wastewater treatment.@ 2019 Yu-Hua Zhao et al.. This is an Open Access article distributed under the terms of the Creative Commons Attribution-Noncommercial 4.0 International License, permitting all non-commercial use, distribution, and reproduction in any medium, provided the original work is properly cited and acknowledged.

\section{Introduction}

Granular carbon is an inexpensive material frequently serving as biocarrier or adsorbent for heavy metals and organic compounds in wastewater treatment process (Cornelissen et al., 2005). Granular activated carbon addition into the batchmode anaerobic sludge digestion reactor could significantly accelerate substrate consumption and methane production (Yang et al., 2017). Biochar derived from rice straw can be applied to adsorb the endocrine disrupter nonylphenol (NP), and thus accelerating its biodegradation (Lou et al., 2015). However, granular carbon particles, particularly ultrafine particles $(<5 \mu$ in diameter $)$, create problems during screening and tend to float in water (Vijayalakshmi and Raichur, 2003). Moreover, it is difficult to separate or filter fine carbon particles from aquatic systems. For example, Wu et al. reported that granular activated carbon in the hybrid microfiltration process appeared to release micro- and nanoscaled fine carbon particles, which would form potential foulants (Wu et al., 2015). These fine carbon particles are cut down by hydrodynamic shear forces and form carbon-bacteria complexes (Zhao et al., 2015). Hence, fine particle grading, separation, and recycling, related to economic benefits and environmental effects, require great attention and in-depth study.

Fine carbon particles may act as a condensation nucleus of organic substances, therefore, flocculation or coagulation can alternatively be used to increase the particle sizes and then enhance the settling rates and separation process (Vijayalakshmi and Raichur, 2003). Flocculating agents are widely used in various industrial fields including wastewater treatment, dredging, and fermentation processes (Kurane et al., 1986). Flocculants synthesized by conventional chemical methods, such as aluminum sulfate and polyethylenimine, have many drawbacks (e.g., biotoxicity, narrow applicability, and lack of degradability). Whereas, bioflocculants, secreted by microbes during their growth, are usually biodegradable and environmentally friendly and are adaptable to $\mathrm{pH}$ variation (Salehizadeh and Shojaosadati, 2001). They have wide industrial applications in various wastewater treatment processes including sludge dewatering and swine wastewater pretreatment (Guo and Ma, 2015), heavy metal treatment (Abdel-Halim and Al-Deyab, 2011), and tannery wastewater containing organic materials (Yang et al., 2015). For example, it was reported that bioflocculant MBF-G22 produced by Pseudomonas sp. G22 showed high flocculanting efficiency of microalgae (95.7\%) at a dosage of $80 \mathrm{mg} / \mathrm{L}$ (Guo et al., 2018). Using bioflocculants for the aggregation and precipitation of granular carbon particles in wastewater could constitute a novel, cost-effective, and environmentally-friendly approach. Bioflocculants can induce particle-to-particle flocculation through the formation of bridges, resulting in the agglomeration and settling of 
suspended fine particles.

Despite these advantages, the practical application of bioflocculants for the remediation of toxins in polluted aquatic environments has been proven challenging. Effective strains that can be cultivated in low-cost medium with maximum rates of bioflocculant production and autoflocculating strains that can be harvested both are attractive research topics (Zhuang et al., 2012; Lee and Chang, 2018). The bioflocculant fermentation of Rhodococcus sp. R3 was optimized by active sludge alkaline-thermal treatment, with chemical oxygen demand and ammonium removal rates of $87.9 \%$ and $86 \%$, respectively (Guo et al., 2013). Hydrolysates of other agricultural wastes, such as corn stover (Wang et al., 2013) and peanut hulls (Liu et al., 2016), have also been applied as inexpensive carbon sources for bioflocculants production. Guo et al. prepared a bioflocculant from hydrolysed rice stover using diluted sulfuric acid and hypothesized that the charge neutralization and inter-particle bridging led to the enhanced performance (Guo et al., 2015).

The increasing global demand for sustainable resources necessitates the effective utilization of agro-wastes. Wheat bran, an inexpensive substrate, is produced worldwide in large quantities (approximately $>150$ million tons) as a by-product of white wheat flour milling for human consumption (Prückler et al., 2014; Bergmans et al., 1996). Moreover, wheat bran contains nutrients, such as non-starch polysaccharides, starch, proteins, and lignin (Maes and Delcour, 2001). Clostridium beijerinckii ATCC 55025 could produce $11.8 \mathrm{~g} / \mathrm{L} \mathrm{ABE}$ (acetone, butanol and ethanol) with the hydrolysate of wheat bran pretreated with dilute sulfuric acid as the substrate (Liu et al., 2010). Moreover, it was reported that alkaline pretreated wheat bran could be a great potential alternative feedstock with no further detoxification for polyhydroxybutyrate production (Annamalai and Sivakumar, 2016). However, there was little research focused on using wheat bran hydrolysate as an economical and environmental friendly way for bioflocculant production.

In this study, we isolated a novel bioflocculant-producing strain, Bacillus sp. R1, from activated swage sludge, determined the optimal fermentation conditions with wheat bran hydrolysate as substrate, evaluated the characteristics of the bioflocculant BF-R1, and subsequently examined its applications in granular biochar particles removal. According to our literature research, no previous report has investigated the use of wheat bran hydrolysate in bioflocculant production.

\section{Materials and Methods}

\subsection{Materials}

NP (CAS 84852-15-3, molecular weight: 220.35) was purchased from Aladdin Co. Ltd. (Shanghai, China). Wheat bran and granular carbon were purchased from Jinhua (Zhe- jiang, China). All other general compounds were of analytical grade.

\subsection{Isolation and Identification of the Bioflocculant-Producing Strain}

Activated sludge was collected from a wastewater treatment plant (Wenzhou, Zhejiang, China) and used to isolate strains capable of producing bioflocculants. Generally, one milliliter of sludge sample was serially diluted using sterilized distilled water and then spread onto $0.5 \times$ Luria-Bertani (LB) medium agar plates containing (per L) 5.0 g tryptone, 2.5 $\mathrm{g}$ yeast extract, $5.0 \mathrm{~g}$ sodium chloride, and $20 \mathrm{~g}$ agar. The formed single colonies were inoculated into $100 \mathrm{~mL}$ liquid flocculating strain screening (FSS) medium and incubated in a rotary shaker at $200 \mathrm{rpm}$ and $30{ }^{\circ} \mathrm{C}$ for $24 \mathrm{~h}$. The FSS medium was prepared as previously described (Yang et al., 2015) and contained (per L): $0.5 \mathrm{~g}$ glucose, $0.5 \mathrm{~g}$ starch, 0.5 $\mathrm{g}$ yeast extract, $0.5 \mathrm{~g}$ peptone, $0.5 \mathrm{~g}$ casein, $0.3 \mathrm{~g} \mathrm{~K}_{2} \mathrm{HPO}_{4}$, and $0.05 \mathrm{~g} \mathrm{MgSO}_{4} \cdot 7 \mathrm{H}_{2} \mathrm{O}(\mathrm{pH} 7.0)$. Ultimately, four large and viscous colonies were chosen and stored at $-80{ }^{\circ} \mathrm{C}$ in $20 \%$ glycerol.

The strain showing the highest flocculation efficiency, named R1, was selected for further investigation. The genomic DNA of R1 was extracted using a Genomic DNA Kit (Sangon Biotech Co. Ltd.) according to the manufacturer's instructions. Universal bacterial primers 27F (5'-AGAGTTTGATCATGGCTCAG-3') and 1492R (5'TACGGTTACCTGTTACGACTT-3') were used to amplify the $16 \mathrm{~S}$ rDNA gene with the following PCR program: predenaturation at $95{ }^{\circ} \mathrm{C}$ for $5 \mathrm{~min} ; 30$ cycles of denaturation at $95{ }^{\circ} \mathrm{C}$ for $30 \mathrm{~s}$, annealing at $55^{\circ} \mathrm{C}$ for $30 \mathrm{~s}$, and extension at $72{ }^{\circ} \mathrm{C}$ for $90 \mathrm{~s}$; and a final step at $72{ }^{\circ} \mathrm{C}$ for $5 \mathrm{~min}$. After purification, the $\mathrm{PCR}$ product was sequenced (Sangon Biotech Co. Ltd., Shanghai, China). And the acquired sequence was blasted against the references sequences in the National Center for Biotechnology Information (NCBI) database. Multiple sequence alignments were conducted using CLUSTALX 2.0 software and a phylogenetic tree was then constructed using the neighbor-joining method with MEGA 6.0 software.

\subsection{Flocculating Activity Assay}

The flocculating activity was determined by measuring the flocculation efficiency in jar tests according to previous studies (Zhuang et al., 2012; Guo et al., 2015). $15 \mathrm{mg} \mathrm{CaCl} 2$ and $2.0 \mathrm{mg}$ bioflocculant were added to a $100 \mathrm{~mL}$ kaolin suspension $(5.0 \mathrm{~g} / \mathrm{L})$ after the $\mathrm{pH}$ adjustion to $7.5 \mathrm{using} \mathrm{NaOH}$ or $\mathrm{HCl}$. The reaction mixture was stirred thoroughly for 5 min and then allowed to settle for $5 \mathrm{~min}$. following this, the optical density (OD) of the clarified solution was measured using a spectrophotometer (7320G; Shanghai, China) at 550 $\mathrm{nm}$. A control experiment was conducted in the same manner without the bioflocculant addition. Flocculation activity was 
calculated as described;

$$
F E(\%)=\frac{\left(A_{0}-A_{t}\right)}{A_{0}} \times 100
$$

Where: $\mathrm{A}_{0}$ and $\mathrm{A}_{t}$ are the $\mathrm{OD}_{550}$ values of control and the sample experiment, respectively; FE is the flocculation efficiency of the specified bioflocculant.

\subsection{Preparation of the Wheat Bran Hydrolysate and Bioflocculant Production}

Dried wheat bran was crushed into powder, sieved through 100-mesh screen, and stored in desiccators prior to hydrolysis by diluted sulfuric acid $(1.7 \%, \mathrm{w} / \mathrm{w})$ with a solid-liquid ratio of $1: 10(\mathrm{w} / \mathrm{v})$ at $121{ }^{\circ} \mathrm{C}$ for $1.5 \mathrm{~h}$. After cooling down, the slurry mixture was centrifuged at $10,000 \mathrm{rpm}, 4{ }^{\circ} \mathrm{C}$ for $10 \mathrm{~min}$. Then the supernatant was neutralized to 7.0 by $\mathrm{Ca}(\mathrm{OH})_{2}$ and the generated precipitates was removed by centrifugation at $10,000 \mathrm{rpm}, 4^{\circ} \mathrm{C}$ for $5 \mathrm{~min}$. Subsequently, the supernatant was stored at $4{ }^{\circ} \mathrm{C}$ and used as the sole carbon and nitrogen source for bioflocculant production.

Strain R1 cultured in $0.5 \times \mathrm{LB}$ medium at $30^{\circ} \mathrm{C}$ overnight was treated as the seed broth. Two milliliters of seed culture were then inoculated into $500 \mathrm{~mL}$ of fermentation medium, which was consisted of different concentrations of wheat bran hydrolysate in minimum salt medium (MSM) prepared according to a previous study (Bai et al., 2016). The fermentation product was centrifuged at $12,000 \mathrm{rpm}, 4{ }^{\circ} \mathrm{C}$ for 5 min to remove the cells after $12 \mathrm{~h}$ 's incubation. Two volumes of pre-chilled ethanol were added into the supernatant to precipitate the bioflocculant. The resulting precipitate was washed with $75 \%$ ethanol and lyophilized to obtain the purified bioflocculant.

\subsection{Characterization of the Bioflocculant}

Saccharide, protein, and glycoprotein contents were identified according to the methods described by Zhao et al. (Zhao et al., 2016). Chemical characterization of the samples was analyzed by Fourier transform infrared spectroscopy (FTIR; Nicolet AVatAR 370; Thermo Scientific, Waltham, MA, USA). And the sample spectrum was recorded on the spectrophotometer over a wave number range of $500-4000 \mathrm{~cm}^{-1}$. Differential scanning calorimetry (DSC) analysis (Q2000 V24.11) was conducted to characterize the thermal behaviors of the bioflocculant under a nitrogen gas flow of $80 \mathrm{~mL} / \mathrm{min}$ and a heating rate of $20^{\circ} \mathrm{C} / \mathrm{min}$ from $20^{\circ} \mathrm{C}$ to $280{ }^{\circ} \mathrm{C}$.

\subsection{Fine Carbon Particles Removal in Wastewater}

The dried carbon was crushed into powder and sieved through a 100-mesh screen. Then $150 \mathrm{mg} / \mathrm{L}$ granular carbon was poured into flasks containing $500 \mathrm{mg} / \mathrm{L} \mathrm{NP}$ and cultured at $150 \mathrm{rpm}$ and $25{ }^{\circ} \mathrm{C}$ for $30 \mathrm{~min}$. Next, different amount of bioflocculant was added; the flasks were stirred at 150 rpm for $10 \mathrm{~min}$ and then allowed to settle for $30 \mathrm{~min}$. The upper phase was then sampled in order to measure the residual amount of NP in the aqueous phase after absorption and flocculation by high performance liquid chromatography (HPLC) as previously described (Bai et al., 2017). All measurements were conducted in triplicate. Flocculation activity was observed by measuring the absorbance variation at $550 \mathrm{~nm}$. Furthermore, the morphologies of BF-R1 and the flocculated/non-flocculated granular carbon were characterized using scanning electron microscopy (SEM) (JEOL JSM 5600 LV, Japan).

\subsection{Statistical Analysis}

Results were presented as mean value \pm standard deviation (SD) of the three replicates. One way analysis of variance (ANOVA) followed by Least Significant Difference (LSD) test was performed using SPSS 16.0 software (IBM, Armonk, NY, USA) to determine significant differences in all the parameters. Values were considered to be statistically significant at $p<0.05$. Figures were prepared using ORIGIN 8.0 (OriginLab Corporation, Northampton, MA, USA).

\section{Results and Discussion}

\subsection{Isolation and Identification of Bioflocculant-Producing Strain}

In this study, a bacterial strain, possessing relatively high flocculant productivity was isolated from activated sewage sludge (NCBI database accession number MH470262). After 16S rDNA alignment and BLAST, it showed that this strain was phylogenetically closely related to Bacillus amyloliquefaciens (Figure 1). Thus, we named this bacterium and its produced flocculant as Bacillus sp. R1 and BF-R1, respectively. Bacteria strains capable of fermenting bioflocculants, including Rhodococcus erythropolis (Guo and Ma, 2015), Ochrobacterum ciceri (Wang et al., 2013), Paenibacillus jamilae (Zhong et al., 2018), Sphingomonas yabuuchiae (Zhong et al., 2014), Pseudomonas veronii (Liu et al., 2016), and Bacillus subtilis (Wu and Ye, 2007), have been previously reported. Different fungi have also been shown to produce bioflocculants, such as Levure casseeuse (Poelmans and Swinnen, 2011) and Aspergillus parasiticus (Deng et al., 2005). Different types of bioflocculants can be applied in the disposal of heavy metal ions, drinking water, wastewater, and polluted soil. Guo et al. demonstrated that the bioflocculant with a main backone of polysaccharides efficiently removed $99.2 \% 2 \mathrm{mg} / \mathrm{L}$ arsenite (at $60 \mathrm{~min}$ ) through bridging mechanisms (Guo and Chen, 2017).

\subsection{The Effect of Wheat Bran Hydrolysate Concentration on BF-R1 Production}

Bioflocculant characteristics usually depends on the bacterial internal features, the compositions of culture medium, 


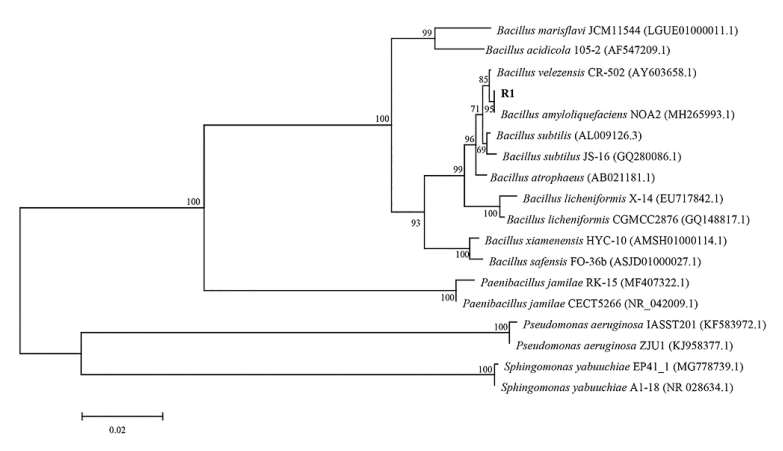

Figure 1. Neighbor-joining phylogenetic tree based on 16S rDNA gene sequences showing the evolutionary position of R1 using MEGA 6.0 software. Bootstrap values (percentages of 1000 replications) are shown at the branch points. The scale bar indicates 0.02 substitutions per nucleotide position (evolutionary distance).

and environmental conditions (Giri et al., 2015). Higher costs related to expensive substrates or lower flocculation efficiency have limited microorganisms application for industrial processes (Yang et al., 2015). Strain R1 produced a maximum of $3.71 \mathrm{~g} / \mathrm{L}$ bioflocculant when supplemented with $200 \mathrm{~mL} / \mathrm{L}$ wheat bran hydrolysate ( $\mathrm{pH}$ 7.0) (Figure 2A). As to our knowledge, this is the first report that wheat bran hydrolysate can be used as the sole carbon and nitrogen source for bioflocculant production. Notably, too high concentrations of wheat bran hydrolysate resulted in significant decrease of bioflocculant production, which may be due to inhibition of microbial activities by toxic by-products in the hydrolysate. It was found that the highest yield of bioflocculant $(4.32 \mathrm{~g} / \mathrm{L})$ was achieved when $500 \mathrm{~mL} / \mathrm{L}$ peanut hull hydrolysate and $3 \mathrm{~g} / \mathrm{L}$ yeast extract were added to the fermentation medium (Liu et al., 2016); while the bioflocculant yield was only $1.25 \mathrm{~g} / \mathrm{L}$ when the hydrolysate was reduced to $200 \mathrm{~mL} / \mathrm{L}$. Swine wastewater was used as raw materials and yielded $3.11 \mathrm{~g} / \mathrm{L}$ bioflocculant after fermentation for 60 $\mathrm{h}$ at $30{ }^{\circ} \mathrm{C}$ and $150 \mathrm{rpm}$ (Guo and Chen, 2017). Thus this procedure can be a novel way to reduce the material cost of bioflocculant production.

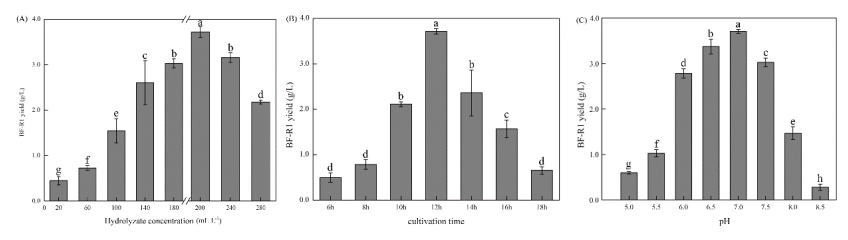

Figure 2. Effects of wheat bran hydrolysate supplement concentration (A), cultivation time (B), and initial $\mathrm{pH}(\mathrm{C})$ on bioflocculant yield of strain R1.

\subsection{The Effects of Initial $\mathrm{pH}$ and Cultivation Time on BF-R1 Production}

Agricultural waste is rich in lignocelluloses and its hydrolysate generally contained reducing sugars, such as glucose and xylose (Liu et al., 2016). However, bacterial fermentation can be inhibited by compounds formed during agricultural waste pretreatment (Liu et al., 2016; Field et al., 2015). Microorganisms generally seemed to require more time for bioflocculant production from agriculture waste than chemical compounds. In our present study, the fermentation time of strain R1 was only $12 \mathrm{~h}$ (Figure 2B), slightly shorter than the findings of Zhuang et al. demonstrating that when Bacillus licheniformis utilized $30 \mathrm{~g} / \mathrm{L}$ molasses as the sole carbon source fermentation time was reduced to $13 \mathrm{~h}$, which was also obviously shorter than other reported fermentation times ranging from 13 to $30 \mathrm{~h}$ (Zhuang et al., 2012; Wang et al., 2013; Guo et al., 2015). Along with cultivation time, polymer quantity monotonically decreased to $0.65 \mathrm{~g} / \mathrm{L}$ at 18 $\mathrm{h}$, possibly due to the consumption as substitute for food during later bacterial growth stages (Wang et al., 2013).

The effect of $\mathrm{pH}$ on flocculant production was evaluated and presented in Figure 2C. Bacillus sp. R1 produced BF$\mathrm{R} 1$ at a $\mathrm{pH}$ range of 5.0-8.5, with the highest flocculant production $(3.71 \mathrm{~g} / \mathrm{L})$ at neutral $\mathrm{pH}$. Cell growth may be inhibited under acidic or alkaline conditions, thus resulting in reduced concentrations of the extracellular flocculant. Pseudomonas veronii L918 exhibits the highest flocculating activity (91.67\%) at pH 7.0 (Liu et al., 2016). The optimal conditions for Sphingomonas yabuuchiae SW-2 bilflocculant fermentation were $425 \mathrm{mg} / \mathrm{L}$ CODCr of chromotropic acid wastewater, an initial $\mathrm{pH}$ of 6.9 , and inoculum size of $7.74 \%$ (Zhong et al., 2014). The salt-tolerant, alkaliphilic strain Bacillus agaradhaerens $\mathrm{C} 9$ exhibited the highest bioflocculant activity at pH 10.2 (Liu et al., 2015). Though different strains produced bioflocculant at specific $\mathrm{pHs}$, too acidic or alkaline conditions may cause cellular stress, consequently leading to inhibition of bioflocculant production. Therefore, cultivation of bioflocculant-producing strain R1 using wheat bran hydrolysate had both economic and environmental benefits.

\subsection{Characterization of Bioflocculant BF-R1}

The Molisch's test showed the purple ring between the concentrated $\mathrm{H}_{2} \mathrm{SO}_{4}$ layer and the bioflocculant layer in the test tube, indicating saccharides existence in BF-R1 (Table 1) (Yang et al., 2015). Saccharides generate furfural or its derivatives via dehydration by concentrated $\mathrm{H}_{2} \mathrm{SO}_{4}$; the derivatives would correspondingly react with $\alpha$-naphthol and generate purple substances. Saccharides are macromolecules and therefore their presence in the bioflocculant may help the bioflocculant bind with pollutants, such as granular carbon, in wastewater (Zhao et al., 2016). Many researches pointed that the bioflocculant main backbone was polysaccharides or proteins. For example, the bioflocculant fermented by Bacillus megaterium G04 with swine wastewater was composed of $85.5 \%$ polysaccharides, $14.3 \%$ proteins, and $0.2 \%$ sugars (Guo and Chen, 2017). Similarly, in this study, BF-R1 contained saccharides, proteins, and glycoproteins.

FTIR analysis (Figure 3) revealed a broad stretching peak 
Table 1. List of possible functional groups from fungal, wood, and wood-immobilized biomass involved in $\mathrm{Pb}(\mathrm{II})$ sorption.

\begin{tabular}{ccc}
\hline $\begin{array}{c}\text { Identification } \\
\text { experiment }\end{array}$ & $\begin{array}{c}\text { Observed } \\
\text { phenomenon }\end{array}$ & Interpretation \\
\hline Molisch reaction & Positive & Contained saccharides \\
Biuret reaction & Positive & Contained proteins \\
Anthrone reaction & Positive & Contained glycoproteins \\
\hline
\end{tabular}

near wavelength $3276.6 \mathrm{~cm}^{-1}$, indicating the presence of primary amino groups (-NH-), one of the main protein groups. Furthermore, the bending vibration peak for the primary amino group (-NH-) at wavelength $835.1 \mathrm{~cm}^{-1}$ indicated the presence of protein in the bioflocculant (Zhao et al., 2016). There was a peak of asymmetrical stretching vibration for $-\mathrm{C}=\mathrm{O}-$ at $1652.8 \mathrm{~cm}^{-1}$, a peak of stretching vibration for $-\mathrm{C}-\mathrm{O}-$ at $1066.5 \mathrm{~cm}^{-1}$, and a peak of bending vibration for -O-H- at $927.6 \mathrm{~cm}^{-1}$ (Guo et al., 2015; Zhao et al., 2016; Zhong et al., 2014; Ugbenyen et al., 2015). The peak at $1539.0 \mathrm{~cm}^{-1}$ for $\mathrm{N}-\mathrm{O}$ bound indicated nitro compounds in BF-R1. An additional peak of stretching vibration for methyl and methylene at $2933.3 \mathrm{~cm}^{-1}$ and a peak of bending vibration for $-\mathrm{C}-\mathrm{H}-$ around $1456.1 \mathrm{~cm}^{-1}$ were also detected (Zhao et al., 2016). In conclusion, FTIR analysis indicated the possible presence of proteins, saccharides, and lipids in the BF-R1 of Bacillus sp. R1 (El-Salam et al., 2017) and that the functional groups induced high binding capacity.

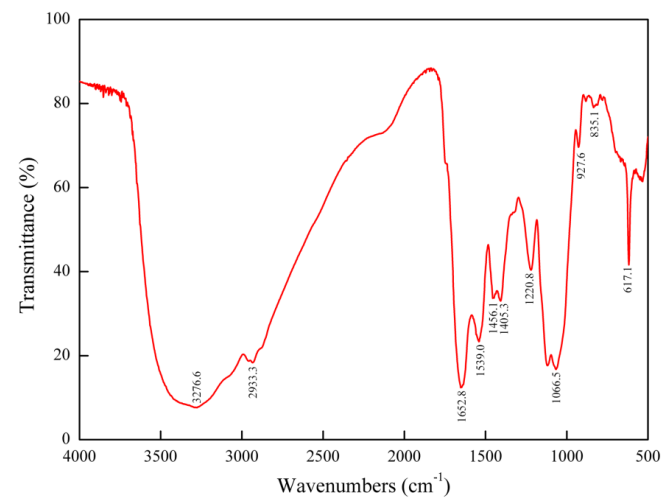

Figure 3. Fourier transform infrared spectrum (FTIR) analysis of the BF-R1 bioflocculant fermented by Bacilllus sp. R1.

Thermal-stable bioflocculants are preferred for industrial applications (Shahadat et al., 2017). Thus, DSC analysis was performed to examine the thermal characteristics of BFR1. DSC thermal analysis demonstrated a characteristic endothermic transition at $151.3{ }^{\circ} \mathrm{C}$, which also indicated the melting point of the bioflocculant. Degradation began above $243.71^{\circ} \mathrm{C}$, indicating that the bioflocculant had good thermal stability, which enables an advantageous bioflocculant under under various thermal conditions. The melting point of the bioflocculant from $B$. licheniformis WSF-1 was determined to be $200-207.5^{\circ} \mathrm{C}$, suggesting that BF-R1 was more stable than previously reported bioflocculants (Jenny et al., 2018).

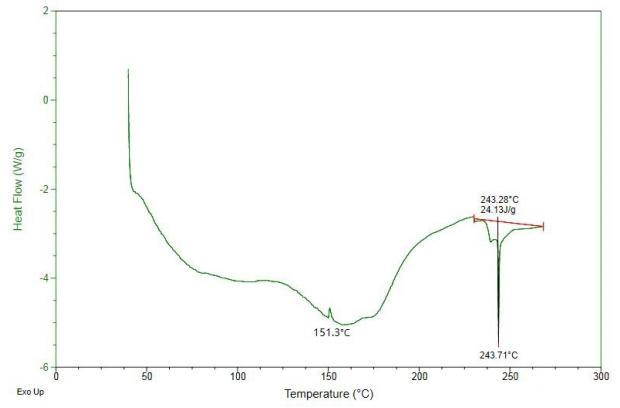

Figure 4. FTIR spectra of sorbents: WP (A) (B) dried fungi (F), and (C) dried wood immobilized with fungi $(\mathrm{WP}+\mathrm{F})$.

\subsection{Application of BF-R1 for the Flocculation of Granular Carbon Particles}

The micrographs of the morphological structure of granular carbon particles, purified BF-R1, and flocculated granular carbon particles covered by BF-R1 were analyzed using SEM (Figure 5). The pure BF-R1 appeared as relatively loose granular structure (Figure 5B), the interaction between BF$\mathrm{R} 1$ and the granular carbon particles resulted into compacted floc formation (Figure 5C-D). Granular carbon particles were attached on the binding site of BF-R1, aggregated by the flocculant, and then precipitated into agglomeration of larger flocs.
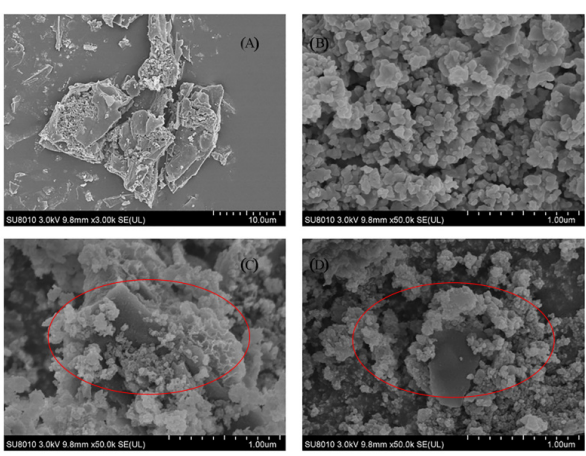

Figure 5. FTIR spectra of WP before (A) and after (B) $\mathrm{Pb}$ (II) treatment, and $\mathrm{WP}+\mathrm{F}$ before $(\mathrm{C})$ and after (D) $\mathrm{Pb}(\mathrm{II})$ treatment.

BF-R1 was added to the reaction system after granular carbon absorbing NP in MSM for specific time periods. Both absorption and flocculation efficiency of granular carbon and the bioflocculant were measured. After 30-40 min, NP was almost completely cleared $(99.85 \%)$ from the sample flasks (Figure 6). In terms of NP removal, there was a synergistic effect between BF-R1 and the granular carbon particles, as no flocculation on NP was observed with only BF-R1 (data not shown). The flocculant aggregated and precipitated the granular carbon particles and the carbon fines to a threedimensional structure with a better settling capacity, thus accelerating NP absorption efficiency. The interaction of phenolic compounds with activated carbon surface was site 
definite and monolayer adsorption (Hamdaoui and Naffrechoux, 2007); therefore, the addition of BF-R1 may facilitate granular particle flocculation and increase the surface area of the complex, thus promoting NP adsorption. Alternatively, the change of the net charge of the bioflocculant-carbon particle complex may also contribute to NP removal (Liu et al., 2016).

Nearly all of the fine particles $(91.00 \%)$ were separated from the water at the dosage of $3.5 \mathrm{~g} / \mathrm{L}$ BF-R1. Notably, the carbon fines were also significantly precipitated. Further increase of BF-R1 addition led to a gently decrease of flocculation activity (Figure S1), which may be caused by the increased electrostatic repulsion between the excessive bioflocculant chains. Additionally, the formerly formed flocs could be deflocculated due to the stronger repulsion force (Guo and Chen, 2017). Granular carbon particles are effective in adsorbing a wide range of organic compounds; meanwhile, carbon fines would reduce water quality because of turbidity and bacterial colonization (Zhao et al., 2015; Campe et al., 1986). Therefore, BF-R1 is capable of controlling the risk posed by granular carbon particles and carbon fines.

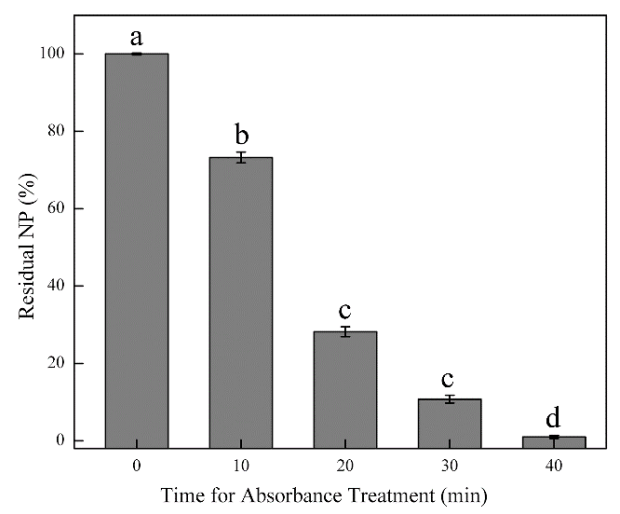

Figure 6. Residual $\mathrm{Pb}(\mathrm{II})$ ion concentration of biosorbents $(\mathrm{WP}, \mathrm{WP}+\mathrm{F}$ ) in contact with 1000 (A), 2000 (B), and $4000 \mu \mathrm{g} / \mathrm{mL} \mathrm{Pb(II)} \mathrm{(C)} \mathrm{for} 30$ minutes in assembled $\mathrm{CF}$ system. Comparison of residual $\mathrm{Pb}(\mathrm{II})$ ion concentration of control (D), WP (E), and WP+F (F) in 1000, 2000, and $4000 \mu \mathrm{g} / \mathrm{mL}$ $\mathrm{Pb}$ (II) concentrations. Means that share at least one similar letter are not significantly different at Tukey's multiple comparisons test $(\mathrm{P}<0.05)$. Bars indicate standard deviation of at least three replicates.

\subsection{Fourier Transform Infrared Spectroscopy}

Possible functional groups of fungal, wood, and woodimmobilized biomass applied in $\mathrm{Pb}$ (II) sorption were assessed through infrared spectroscopy seen in Figure 4. The FTIR spectra shown in Figure 5 depicts plausible $\mathrm{Pb}(\mathrm{II})$ binding sites in comparison to the biomass before and after $\mathrm{Pb}$ (II) treatment.

\section{Conclusion}

In this study, an efficient bioflocculant-producing strain, Bacillus sp. R1, was isolated; this strain fermented wheat bran hydrolysate into a highly efficient and absorbent bioflocculant. Our findings demonstrate, for the first time, bioflocculant production using wheat bran hydrolysate and its effective application in the flocculation of granular carbon particles and carbon fines, which are widely used in the treatment of organic pollutants. A yield of $3.71 \mathrm{~g} / \mathrm{L}$ BF-R1 bioflocculant was achieved when $200 \mathrm{~mL} / \mathrm{L}$ hydrolysate was used as the sole carbon and nitrogen source in $12 \mathrm{~h}$; this would definitely reduce both raw material and time costs. Moreover, BF-R1 aggregated and precipitated the granular carbon particles and the carbon fines to a three-dimensional structure with a better settling capacity, thus accelerating NP absorption efficiency. As the characteristics and flocculation efficiency were examined at the lab-scale in this study, large-scale application tests are essential for industrial application of BF-R1.

\section{Acknowledgement}

This study was supported by the National Key Basic Research Program of China (2015CB150502), the National Natural Science Foundation of China (41671314; 41877114), and the Key Research and Development Program of Zhejiang Province (2015C03011).

\section{Conflict of interest}

There are no conflicts of interest to declare. This study did not involve any human participants.

\section{References}

Cornelissen, G., Gustafsson, O., Buchili, T.D., Jonker, M.T.O., Koelmans, A.A., and Van Noort, P.C.M., 2005. Extensive sorption of organic compounds to black carbon, coal, and kerogen in sediments and soils: Mechanisms and consequences for distribution, bioaccumulation, and biodegradation. Environmental Science and Technology, 39(18), 68816895.

https://doi.org/10.1021/es050191b

Yang, Y.F., Zhang, Y.B., Li, Z.Y., Zhao, Z.Q., Quan, X., and Zhao, Z.S., 2017. Adding granular activated carbon into anaerobic sludge digestion to promote methane production and sludge decomposition. Journal of Cleaner Production, 149, 11011108.

https://doi.org/10.1016/j.jclepro.2017.02.156

Lou, L.P., Yao, L.D., Cheng, G.H., Wang, L.X., He, Y.F., and Hu, B.L., 2015. Application of rice-straw biochar and microorganisms in nonylphenol remediation: Adsorptionbiodegradation coupling relationship and mechanism. PLoS ONE, 10(9), e0137467. https://doi.org/10.1371/journal.pone.0137467

Vijayalakshmi, S.P. and Raichur, A.M., 2003. The utility of Bacillus subtilis as a bioflocculant for fine coal. Colloids and Surfaces B: Biointerfaces, 29(4), 265-275. https://doi.org/10.1016/S0927-7765(03)00005-5

Wu, B., Wong, P.C.Y., and Fane, A.G., 2015. The potential roles of granular activated carbon in anaerobic fluidized membrane 
bioreactors: Effect on membrane fouling and membrane integrity. Desalination and Water Treatment, 53(6), 14501459. https://doi.org/10.1080/19443994.2014.943057

Zhao, J.H., Chen, W., Zhao, Y.Q., Liu, C.Y., and Liu, R.B., 2015. $\mathrm{UV} / \mathrm{TiO}_{2}$ photocatalytic disinfection of carbon-bacteria complexes in activated carbon-filtered water: Laboratory and pilot-scale investigation. Environmental Letters, 50(12), 1274-1281.

https://doi.org/10.1080/10934529.2015.1055155

Kurane, R., Takeda, K., and Suzuki, T., 1986. Screening for and characteristics of microbial flocculants. Agricultural and Biological Chemistry, 50(9), 2301-2307. https://doi.org/10.1080/00021369.1986.10867746

Salehizadeh, H. and Shojaosadati, S.A., 2001. Extracellular biopolymeric flocculants: Recent trends and biotechnological importance. Biotechnology Advances, 19(5), 371-385. https://doi.org/10.1016/S0734-9750(01)00071-4

Guo, J.Y. and Ma, J., 2015. Bioflocculant from pre-treated sludge and its applications in sludge dewatering and swine wastewater pretreatment. Bioresource Technology, 196, 736-740. https://doi.org/10.1016/j.biortech.2015.07.113

Abdel-Halim, E.S. and Al-Deyab, S.S., 2011. Removal of heavy metals from their aqueous solutions through adsorption onto natural polymers. Carbohydrate Polymers, 84(1), 454-458. https://doi.org/10.1016/j.carbpol.2010.12.001

Yang, Q.H., Ming, H.M., Zhao, X.X., Zhang, J., Wei, Z., Zhao, C.Q., and Guan, X.Q., 2015. Screening of bioflocculant and preliminary application to treatment of tannery wastewater. Journal of Residuals Science and Technology, 12(3), 177181. http://doi.org/10.12783/issn.1544-8053/12/3/8

Guo, H.P., Hong, C.T., Zhang, C., Zheng, B.S., Jiang, D., and Qin, W.S., 2018. Bioflocculants' production from a cellulasefree xylanase-producing Pseudomonas boreopolis G22 by degrading biomass and its application in cost-effective harvest of microalgae. Bioresource Technology, 255, 171-179. https://doi.org/10.1016/j.biortech.2018.01.082

Zhuang, X.L., Wang, Y.P., Li, Q.B., Yan, S., and He, N., 2012. The production of bioflocculants by Bacillus licheniformis using molasses and its application in the sugarcane industry. Biotechnology and Bioprocess Engineering, 17(5), 10411047. https://doi.org/10.1007/s12257-012-0213-0

Lee, D.J. and Chang, Y.R., 2018. Bioflocculants from isolated stains: A research update. Journal of the Taiwan Institute of Chemical Engineers, 87, 211-215. https://doi.org/10.1016/j.jtice.2018.03.037

Guo, J.Y., Yang, C.P., and Zeng, G.M., 2013. Treatment of swine wastewater using chemically modified zeolite and bioflocculant from activated sludge. Bioresource Technology, 143, 289-297. https://doi.org/10.1016/j.biortech.2013.06.003

Wang, L., Ma, F., Lee, D.J., Wang A.J., and Ren, N.Q., 2013. Bioflocculants from hydrolysates of corn stover using isolated strain Ochrobactium ciceri W2. Bioresource Technology, 145, 259-263. https://doi.org/10.1016/j.biortech.2012.11.020

Liu, W.J., Hao, Y., Jiang, J.H., Zhu, A.H., Zhu, J.R., and Dong, Z., 2016. Production of a bioflocculant from Pseudomonas veronii L918 using the hydrolyzate of peanut hull and its application in the treatment of ash-flushing wastewater generated from coal fired power plant. Bioresource Technology, 218, 318-325.

https://doi.org/10.1016/j.biortech.2016.06.108

Guo, J.Y., Yu, J., Xin, X., Zou, C.W., Cheng, Q.F., Yang, H.J., and Nengzi, L.C., 2015. Characterization and flocculation mechanism of a bioflocculant from hydrolyzate of rice stover. Bioresource Technology, 177, 393-397. https://doi.org/10.1016/j.biortech.2014.11.066

Prückler, M., Sibenhandl-Ehn, S., Apprich, S., Höltinger, S., Haas, C., Schmid, E., and Kneifel, W., 2014. Wheat bran-based biorefinery 1: Composition of wheat bran and strategies of functionalization. LWT - Food Science and Technology, 56(2), 211-221. https://doi.org/10.1016/j.lwt.2013.12.004

Bergmans, M.E.F., Beldman, G., Gruppen, H., and Voragen, A.G.J., 1996. Optimization of the selective extraction of (glucurono)arabinoxylans from wheat bran: use of barium and calcium hydroxide solution at elevated temperatures. Journal of Cereal Science, 23(3), 235-245. https://doi.org/10.1006/jcrs.1996.0024

Maes, C. and Delcour, J.A., 2001. Alkaline hydrogen peroxide extraction of wheat bran non-starch polysaccharides. Journal of Cereal Science, 34(1), 29-35. https://doi.org/10.1006/jcrs.2001.0377

Liu, Z.Y., Ying, Y., Li, F.L., Ma, C.Q., and Xu P., 2010. Butanol production by Clostridium beijerinckii ATCC 55025 from wheat bran. Journal of Industrial Microbiology and Biotechnology, 37(5), 495-501. https://doi.org/10.1007/s10295-010-0695-8

Annamalai, N. and Sivakumar, N., 2016. Production of polyhydroxybutyrate from wheat bran hydrolysate using Ralstonia eutropha through microbial fermentation. Journal of Biotechnology, 237, 13-17. https://doi.org/10.1016/j.jbiotec.2016.09.001

Bai, N.L., Wang, S., Abuduaini, R., Zhu, X.F., and Zhao, Y.H., 2016. Isolation and characterization of Sphingomonas sp. Y2 capable of high-efficiency degradation of nonylphenol polyethoxylates in wastewater. Environmental Science and Pollution Research, 23(12), 12019-12029. https://doi.org/10.1007/s11356-016-6413-y

Zhao, C.Q., Zhao, X.X., Gu, H.B., Zhang, J., Zou, W., Liu, J., and Yang, Q.H., 2016. Qualitative analysis of components of bioflocculant prepared with Bacillus fusiformis for the treatment of tannery wastewater. Clean Technologies and Environmental Policy, 18(3), 973-978. https://doi.org/10.1007/s10098-015-1085-8

Bai, N.L., Abuduaini, R., Wang, S., Zhang, M.N., Zhu, X.F., and Zhao, Y.H., 2017. Nonylphenol biodegradation characterizations and bacterial composition analysis of an effective consortium NP-M2. Environmental Pollution, 220, 95-104. https://doi.org/10.1016/j.envpol.2016.09.027

Zhong, C.Y., Cao, G., Rong, K., Xia, Z.W., Peng, T., Chen, H.G., and Zhou, J.G., 2018. Characterization of a microbial polysaccharide-based bioflocculant and its anti-inflammatory and pro-coagulant activity. Colloids and Surfaces B: Biointerfaces, 161, 636-644. https://doi.org/10.1016/j.colsurfb.2017.11.042

Zhong. C.Y., Xu, A.H., Chen, L., Yang, X.H., Yang, B.K., Hong, W.T., Mao, K.W., Wang, B.Y., and Zhou, J.G., 2014. Production of a bioflocculant from chromotropic acid waste water 
and its application in steroid estrogen removal. Colloids and Surfaces B: Biointerfaces, 122, 729-737.

https://doi.org/10.1016/j.colsurfb.2014.08.006

Wu, J.Y. and Ye, H.F., 2007. Characterization and flocculating properties of an extracellular biopolymer produced from a Bacillus subtilis DYU1 isolate. Process Biochemistry, 42(7), 1114-1123. https://doi.org/10.1016/j.procbio.2007.05.006

Poelmans, E. and Swinnen, J., 2011. A brief economic history of beer. In J.F.M. Swinnen (ed.), The Economics of Beer, 3-28, Oxford: Oxford University Press.

http://doi.org/10.1093/acprof:oso/9780199693801.003.0001

Deng, S.B., Yu, G., and Ting, Y.P., 2005. Production of a bioflocculant by Aspergillus parasiticus and its application in dye removal. Colloids and Surfaces B: Biointerfaces, 44(4), 179186. https://doi.org/10.1016/j.colsurfb.2005.06.011

Guo, J.Y. and Chen, C., 2017. Removal of arsenite by a microbial bioflocculant produced from swine wastewater. Chemosphere, 181, 759-766. https://doi.org/10.1016/j.chemosphere.2017.04.119

Giri, S.S., Harshiny, M., Sen, S.S., Sukumaran, V., and Park, S.C., 2015. Production and characterization of a thermostable bioflocculant from Bacillus subtilis F9, isolated from wastewater sludge. Ecotoxicology and Environmental Safety, 121, 45-50. https://doi.org/10.1016/j.ecoenv.2015.06.010

Field, S.J., Ryden, P., Wilson, D., James, S.A., Roberts, I.N., Richardson, D.J., Waldron, K.W., and Clarke, T.A., 2015. Identification of furfural resistant strains of Saccharomyces cerevisiae and Saccharomyces paradoxus from a collection of environmental and industrial isolates. Biotechnology for Biofuels, 8(1), 33. https://doi.org/10.1186/s13068-015-0217-z

Liu, C., Wang, K., Jiang, J.H., Liu, W.J., and Wang, J.Y., 2015. A novel bioflocculant produced by a salt-tolerant, alkaliphilic and biofilm-forming strain Bacillus agaradhaerens C9 and its application in harvesting Chlorella minutissima UTEX2341. Biochemical Engineering Journal, 93, 166-172. https://doi.org/10.1016/j.bej.2014.10.006
Yang, Q.H., Zhao, X.X., Zhang, J., Wang, Y., Zou, W., and Ming,H.M., 2015. Components of a bioflocculant for treating tannery wastewater. Journal of Residuals Science and Technology, 12(2), 99-103. http://doi.org/10.12783/issn.1544-8053/12/2/9

Ugbenyen, A.M., Vine, N., Simonis, J.J., Basson, A.K., and Okoh, A.I., 2015. Characterization of a bioflocculant produced from the consortium of three marine bacteria of the genera Cobetia and Bacillus and its application for wastewater treatment. Journal of Water Sanitation and Hygiene for Development, $5(1), 81-88$.

https://doi.org/10.2166/washdev.2014.181

El-Salam, A. E.A., Abd-EI-Haleem, D., Youssef, A.S., Zaki, S., Abu-Elreesh, G., and El-Assar, S.A., 2017. Isolation, characterization, optimization, immobilization and batch fermentation of bioflocculant produced by Bacillus aryabhattai strain PSK1. Journal of Genetic Engineering and Biotechnology, 15(2), 335-344. https://doi.org/10.1016/j.jgeb.2017.07.002

Shahadat, M., Teng, T.T., Rafatullah, M., Shaikh, Z.A., Sreekrishnan, T.R., and Ali, S.W., 2017. Bacterial bioflocculants: A review of recent advances and perspectives. Chemical Engineering Journal, 328, 1139-1152. https://doi.org/10.1016/j.cej.2017.07.105

Jenny, A.S., Vidyadharani, G., Santhosh, S., and Dhandapani, R., 2018. Optimization and Characterisation of Thermo Stable Exopolysaccharide Produced from Bacillus licheniformis WSF-1 Strain. Journal of Polymers and the Environment, 26(9), 3824-3833. https://doi.org/10.1007/s10924-018-1261-0

Hamdaoui, O. and Naffrechoux, E., 2007. Modeling of adsorption isotherms of phenol and chlorophenols onto granular activated carbon: Part I. Two-parameter models and equations allowing determination of thermodynamic parameters. Journal of Hazardous Materials, 147(1), 381-394. https://doi.org/10.1016/j.jhazmat.2007.01.021

Camper, A.K., LeChevallier, M.W., Broadaway, S.C., and McFeters, G.A., 1986. Bacteria associated with granular activated carbon particles in drinking water. Applied and Environmental Microbiology, 52(3), 434-438. http://aem.asm.org/content/52/3/434 


\section{Supplementary information}

Figure S1

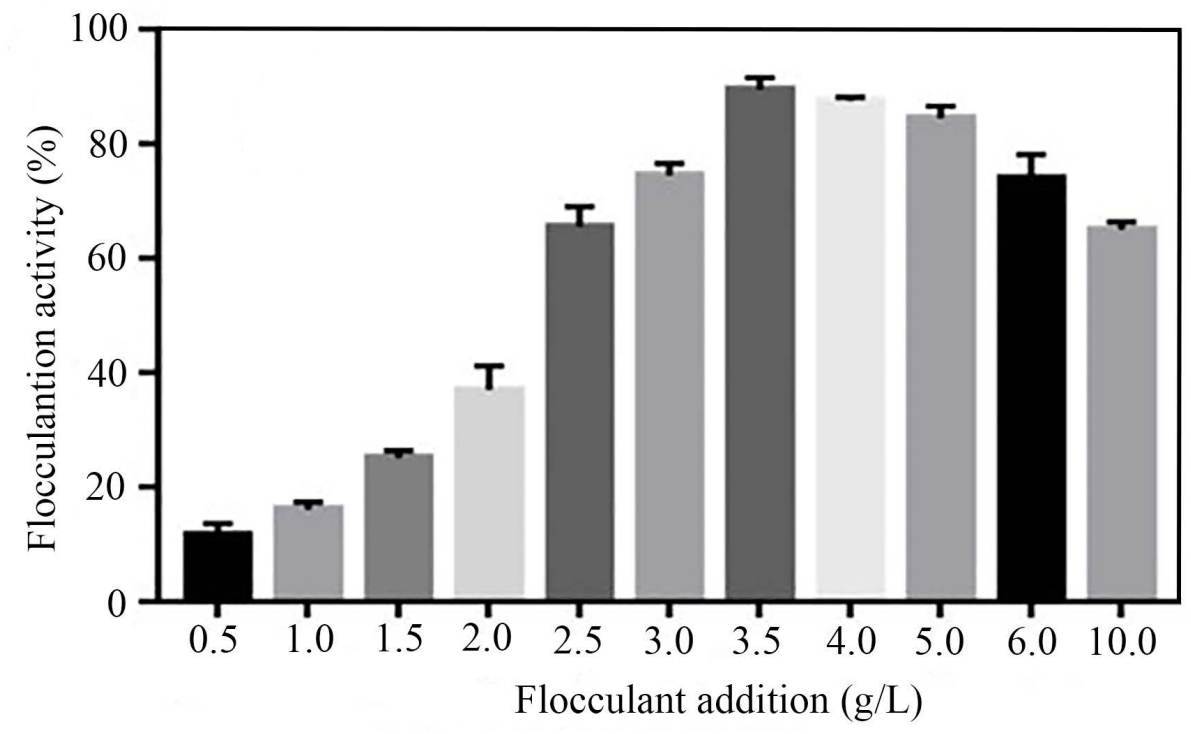

